\title{
El holocausto del periodismo baenense
}

institucional.us.es/ambitos/

\section{Francisco Expósito Extremera}

fexposito@cordoba.elperiodico.com

English Version: The holocaust journalism of Baena in 1936

\section{Resumen}

El golpe de Estado de Francisco Franco en 1936 desencadenó una persecución de periodistas que se vieron vinculados al bando nacional o al republicano. Tres grandes articulistas de Baena, un municipio de Córdoba (España), sufrieron fatales consecuencias. Antonio Bermúdez Cañete, corresponsal de El Debate en la Alemania nazi, enviado especial a la guerra italoabisinia y diputado en 1936 por la CEDA, fue asesinado ese año en la Checa de Bellas Artes de Madrid. Fernando Vázquez Ocaña, diputado socialista en 1933, portavoz del consejo de ministros de Juan Negrín, biógrafo de García Lorca, tuvo que exiliarse en 1939 y no regresó

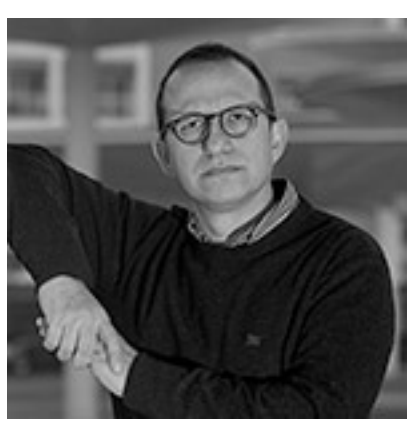
jamás a España. Manuel Piedrahita Ruiz, que estudió en la escuela de periodismo

de El Debate y dirigió periódicos en Zamora, Jaén y Baena, fue asesinado en Baena por los republicanos. El autor analiza el exterminio de algunos de los grandes periodistas andaluces del primer tercio del siglo XX y las consecuencias del levantamiento militar en otros profesionales vinculados a la prensa local y nacional.

\section{Palabras clave}

Periodismo, periodistas, Segunda República, Franco, holocausto, Baena.

\section{Abstract}

A hunt of journalists linked to the national band or the republican one was unchained in 1936 by the Francisco Franco's military coup. Three important columnists from Baena, a village in Cordoba (Spain) suffered disastrous consequences. Antonio Bermúdez Cañete, corresponsal from El Debate en la Alemania nazi, special correspondent in the Italoabisinian war and CEDA diputy in 1936 was assisinated in that year in the Checa of

Bellas Artes in Madrid. Fernando Vázquez Ocaña, socialist deputy in 1933, spokesperson of the Ministers council of Juan Negrín and Garcia Lorca's biographer, went into exile in 1939 and he never came back Spain. Manuel Piedrahita Ruiz, who studied in the journalism school of El Debate and managed newspapers in Zamora, Jaén and Baena, was assassinated in Baena by the republican side. The author analyses the extermination of some of relevant Andalusian journalists in the first third of twentieth century and the military uprising consequences reflected in other professionals linked to local and national press.

\section{Keywords}

Journalism, journalists, Second Republic, Franco, holocaust, Baena.

\section{INTRODUCCIÓN}

¿Qué piensa si un día le dicen que tiene que optar por un camino o por otro y sabe que la decisión que tome le separará de algunos de sus familiares y de sus mejores amigos? Y, lo peor de todo, en esos momentos no gobierna la ley, sino la desconfianza, el miedo y la venganza. En 1936, el año que comenzó a sepultarse la libertad de expresión en España, tres periodistas de Baena (Córdoba) fueron enterrados: Antonio Bermúdez Cañete, Manuel Piedrahita Ruiz y Ramón de Prado Santaella. Otros sobrevivieron, porque pudieron escapar (Fernando Vázquez Ocaña), encontraron la ayuda de alguna persona para salvarse (Antonio de los Ríos) o también hubo quien se alió desde los inicios con el movimiento golpista (Daniel Aguilera Camacho). Todos eran baenenses. La historia del periodismo aún tiene una deuda con ellos. 
Lo que ocurrió en Baena el 28 de julio de 1936 es uno de los grandes dramas de la historia de España, un auténtico holocausto. Un joven abogado, Manuel Cubillo Jiménez, perdió a su mujer y a tres hijos en el asilo de San Francisco, víctimas del bando republicano (1). Era la reacción ante la matanza de decenas de obreros ese mismo día en la plaza del Ayuntamiento por el bando nacional. Poco después de la tragedia del 28 de julio de 1936, Queipo de Llano justificaba la represión en un discurso pronunciado el 31 de julio:

“(...) No hay duda que Córdoba está cercada y próxima a caer en manos del enemigo. ¡Qué horror! Pero no ha sido sólo por ese lado, sino que ayer mismo operaron también los soldaditos de Córdoba hacia Baena, en donde los marxistas han cometido verdaderos horrores, crímenes monstruosos que no se pueden citar por no desprestigiar a nuestro pueblo, y produjeron después de ser tomada Baena el castigo que es natural cuando las tropas están poseídas de la indignación que producen esos crímenes. Baste decir que se encontraron varios niños colgados de las ventanas por los pies (...)" (ABC, 1-8-1936).

La barbarie fue practicada por los dos bandos, aunque uno fue condenado entonces y otro recordado como ejemplo de la cruzada contra el comunismo. Mientras los terribles hechos ocurridos en el asilo de San Francisco fueron utilizados por la propaganda franquista para denunciar la violencia del bando republicano, desde personajes unidos al régimen dictatorial como Queipo de Llano, José María Pemán o el nazi Goebbels, se ocultaba el drama que causaron los golpistas durante la guerra y la cruel posguerra, que practicó la eliminación selectiva y la humillación de aquellas personas que tuvieron algún familiar señalado en la República o eran víctimas de cuentas pendientes por cuestiones personales. Algunos baenenses, que estaban bien posicionados socialmente, no tuvieron escrúpulos e incrementaron sus bienes acaparando los que le fueron arrebatados a los republicanos. La cifra de víctimas mortales nunca se conocerá con exactitud. La última aproximación la hizo Arcángel Bedmar manejando distintas fuentes (2). El historiador jiennense estima que la represión franquista ocasionó la muerte de 361 en Baena durante la guerra, a los que hay que unir 43 fusilados en la posguerra, 18 fallecidos en cárceles y batallones de trabajadores y 14 en campos nazis. A estas víctimas mortales hay que añadir aquellos que sufrieron distintas penas en cárceles, que ascendieron a 125; en batallones, que fueron 172 o en campos de concentración, 36. Además, los jueces militares pidieron informes en la posguerra de 202 baenenses y 199 se vieron sometidos a expedientes de incautación de bienes y de responsabilidades políticas. Asimismo, sitúa en 99 los muertos vinculados al bando nacional.

Resulta curioso que hasta hace pocos meses Franco tuviera aún la medalla de oro de Baena, como Saenz de Buruaga, el militar que se encargó de amortajar la Segunda República en el municipio cordobés y al que secundó uno de los hombres más sanguinarios de la historia de la antigua villa, Pascual Sánchez, medalla de plata, una presea manchada de sangre que relució durante muchas décadas y que hasta un hijo suyo quiso heredar para gloria de su familia. Hace 80 años, el resultado inasumido de unas elecciones, que dieron la victoria al Frente Popular, derrumbó ilusiones y agujereó los sueños de muchos españoles (3).

Vázquez Ocaña describía en 1940 el drama de lo ocurrido en el país:

"Hoy España está llena de muertos. Muertos, quietos para siempre, y muertos que andan. Nuestros muertos y sus matadores (...). ¡ Pobres amigos! Donde triunfó el movimiento nacional la intolerancia fue abriendo los círculos infernales, cada vez más amplios, de las represalias” (Vázquez Ocaña, 2007: 142).

El terror al que se sometió a la población el franquismo la describió Vázquez Ocaña:

"En nombre de la unidad española, la ciudad senequista (se refería a Córdoba) era expurgada de hombres pensantes, soñadores o revolucionarios. En pleno siglo XX trascendía un vaho mortal, un terror negro. Por la noche, las calles solitarias se poblaban de gritos. Eran las cuadrillas de buscadores de 'rojos'. Y el río, el gran río lírico, parecía que lloraba, que murmuraba los salmos del Eclesiastés. El tremendo error de los totalitarios es haber sembrado de muertos España. Entre los muertos, los inocentes le brindan al porvenir la fatalidad redentora de su sangre. Nunca se puede nada, de manera perdurable, contra el vero pueblo. Levantar un imperio y una nación florida sobre un osario, sobre una sociedad enflaquecida y arruinada, es empresa de dioses y no es de creer que los dioses sean aficionados al macabro humorismo" (Vázquez Ocaña, 2007: 144). 


\section{LOS PERIÓDICOS REPUBLICANOS EN BAENA}

El alzamiento militar acabó con la libertad de expresión, la cultura se convirtió en títere de la sinrazón y el misticismo. En las décadas siguientes interesaban más los homenajes a los desaparecidos del bando vencedor y se exaltaba el franquismo. Hasta la constitución de la asociación Amigos del Arte en 1959, una anormalidad entre tanto silencio obligado, fueron escasas las propuestas periodísticas en Baena, solo alguna revista de feria y de Semana Santa. Fue entonces cuando esta sociedad impulsó una revista cultural, Adela, que en el segundo ejemplar pasó a denominarse Tambor y se convertiría en una de las más destacadas de la provincia de Córdoba en los años sesenta. Como sucedió en otras muchas localidades, durante la posguerra y hasta llegar a los años ochenta del siglo XX, se ocultó el recuerdo de cualquier periódico republicano, ya fuera de izquierdas o de derechas. No había escenario para el debate. Cerca de una decena de periódicos se llegaron a distribuir en Baena entre 1930 y 1936, llegando a coincidir tres en 1931: La Defensa, Todos y Hoy (4). Aunque la censura fue habitual en la Segunda República (Sinova, 2006: 417), el escenario de entonces no pudo compararse a lo que sucedió tras el golpe de Estado, cuando desapareció cualquier posibilidad de expresión crítica.

Durante los meses anteriores a la proclamación de la Segunda República y durante su vigencia se publicaron en Baena los periódicos Regeneración, La Defensa, Todos, Hoy, Nuevas, Lex, El Sábado y Lema.

Regeneración (1924-1930) fue uno de los periódicos que tuvieron una existencia más dilatada en la primera mitad del siglo XX en la localidad cordobesa. Fundado a finales de 1924, en él colaboró asiduamente Manuel Piedrahita Ruiz.

La Defensa (1930-1931) apareció el 24 de abril de 1930. Dirigido por Antonio de los Ríos Urbano, su fundador y redactor jefe fue Manuel Piedrahita Ruiz, que abandonaría pronto el proyecto. El 11 de julio de 1931 se convierte en "Órgano de la Agrupación Socialista local". Mantendrá un agrio enfrentamiento con el semanario Todos.

Todos (1931-1932)fue promovido por un grupo de conservadores del municipio para responder a La Defensa. Su primer número se publicó el 26 de junio de 1931. Estaba dirigido por un consejo de redacción.

Hoy (1931-1932) apareció el 12 de agosto de 1931. Su promotor y director era Ramón de Prado.

Nuevas (1934-1935) fue uno de los periódicos más modernos de la provincia de Córdoba. Detrás estaba Manuel Piedrahita Ruiz, que venía de dirigir La Mañana y, después, Nuevas, en Jaén.

Lex (1934) tuvo una breve vida. Sólo se editaron dos números. El primero apareció el 20 de septiembre de 1934 y el segundo el 5 de octubre. Su director fue Antonio de los Ríos.

El sacerdote Bartolomé Carrillo estaba detrás de El sábado, del que no se ha localizado ningún ejemplar. Sólo alguna referencia indirecta en algún periódico:

NUEVO PERIÓDICO. Sabemos está ya ultimada la salida del nuevo periódico que prepara don Bartolomé Carrillo Fernández, arcipreste del partido. Aparecerá desde primero de febrero, seguramente, todos los sábados. Se titula 'El sábado' y constará de cuatro páginas en folio (...) (El Defensor de Córdoba, 17-1-1936).

Por último, Lema (1936) fue impulsado por Ramón de Prado Santaella, que lo dirigió a partir del 10 de abril de 1936. Desde sus inicios, y en su corta vida, fue un gran defensor de la cultura.

\section{LOS PERIODISTAS}

\subsection{Antonio Bermúdez Cañete}

Antonio Bermúdez Cañete (Baena, 1898-Madrid, 1936) es uno de los grandes periodistas andaluces del siglo $X X$, pese a que su trayectoria profesional se ha querido minusvalorar por su afinidad política, no exenta de polémica en algunas etapas de su trayectoria. Amigo de José Antonio Primo de Rivera, fue expulsado de la 
Alemania nazi. Desde su catolicismo practicante, cuestionó la persecución racista que se estaba produciendo con los judíos, pese a ser aliado inicialmente de sus posicionamientos intelectuales. El propio embajador alemán en España, el conde Welczeck, lo calificó el 20 de enero de 1933, a los dos meses de llegar como corresponsal a Alemania de "pro alemán" y "positivo en su actitud". Su relación con los judíos es contradictoria. Bermúdez Cañete fue un intelectual polémico, de enorme carácter, que defendía un Estado unitario, que condenaba el capitalismo judío y defendía la libertad y los negocios de los judíos alemanes durante el nazismo. Como escribiría el profesor Emilio de Diego, Bermúdez Cañete llegó a "rechazar el igualitarismo y el materialismo comunista y arremeter contra las desigualdades sociales basadas en la injusticia" (De Diego et al,. 2008: 137). Detrás estaba siempre la defensa del hombre: "judío, socialista, nazi o comunista, buscando la comprensión de su circunstancia. Porque detrás de todo eso subyace una 'antropología católica' de inspiración evangélica" (De Diego et al,. 2008: 137).

No obstante, de criticar y culpar a los judíos de la situación económica, pasó a advertir de lo que comenzaba a suceder en el régimen nazi, convirtiéndose en una persona incómoda para los alemanes por la imagen que transmitía en sus artículos. Todo lo contrario de lo que sucedió con César González Ruano, que trabajó para los nazis y coincidió con Bermúdez Cañete en Alemania:

Antonio Bermúdez Cañete, periodista cordobés y colega de Ruano, es una historia sensacional en la Europa suicida de los años treinta. Atraído por el ideal, escribió en La Conquista del Estado -la primera publicación fascista en España- y fue el primero en traducir al español capítulos de Mein Kampf. Y, horrorizado por la realidad, no se calló y Joseph Goebbels acabó por expulsarlo de Berlín. ¿Se podía, en el Madrid bipolar de los años treinta, ser de derechas y plantar cara a los nazis? ¿Se podía ser muy de derechas y no quedar succionado por la esvástica? Ruano, en el Berlín de 1933, quedó succionado (Sala Rose y García-Plana, 2014: 129-130).

El odio hacia los descendientes de David se extendía en Alemania, mientras en el resto de Europa una gran corriente intelectual parecía mirar hacia otro lado. España no era menos. La mayoría de la derecha española se alió desde el inicio con el régimen nazi. Bermúdez Cañete sentía una gran atracción por el desarrollo y la cultura germánica. Allí llegó como corresponsal del diario El Debate, convirtiéndose en uno de los grandes periodistas españoles en ese país durante aquellos años. El cronista baenense comenzó a firmar profundas reflexiones sobre la sociedad, la política y la economía. Bermúdez Cañete fue expulsado a finales de enero de 1935. El día 25 recibió una orden del Ministerio de Propaganda alemán exigiéndole que abandonara el país en el plazo máximo de ocho días. Después fue corresponsal en París y fue enviado especial a la guerra italoabisinia. Bermúdez Cañete también dirigió la sección económica del periódico El Debate. Elegido diputado por la CEDA en 1936, se enfrentó desde su visión católica a políticos como la Pasionaria (ésta lo llamaba El Abisinio) y en agosto de ese año fue asesinado en Madrid junto a la checa de Bellas Artes. Todo esto en 38 años de vida para una persona que se mostró como un firme defensor de la Universidad, se formó en Derecho y Economía, hablaba el alemán, el francés y el inglés. "Sin Universidad no hay cultura; ni hay técnica, y sin técnica ni cultura, no hay producción eficaz, ni hay riqueza; ni hay vida", diría en El Debate (23-7-1927). Bermúdez Cañete fue testigo de la marcha de la reina Victoria Eugenia en su exilio de España al viajar con ella en el mismo tren; conoció la llegada al poder de Hitler y el apogeo del nazismo; trató con el emperador etíope Haile Selassie, con Henrich Brüning, Mussolini, Goebbels, Zuloaga o Keynes, entre otros muchos, al sentir y vivir el periodismo con absoluta devoción profesional.

Su trayectoria económica no es menos importante. Rocío Sánchez Lissen, en el libro, dedica un capítulo al periodista cordobés y lo califica como "un destacado economista andaluz y español con formación multidisciplinar” (Sánchez Lissen, 2013: 584). Sánchez Lissen asegura que su obra científica:

\section{(...) está escrita con un lenguaje riguroso y claro, de fácil lectura incluso para el público no especialista. Todo} ello, iba acompañado de una actitud crítica que mostraba a un economista valiente e independiente, preocupado ante todo por resolver nuestros problemas económicos, para que nuestro país se situarse entre los más adelantados del mundo (Sánchez Lissen, 2013: 584).

Muy destacable es su análisis de la situación agraria andaluza y del cultivo del olivar. En sus textos vertió duras críticas contra los terratenientes pasivos y defendió el turismo como uno de los pilares fundamentales de la 
economía española.

\subsection{Fernando Vázquez Ocaña}

Fernando Vázquez Ocaña (Baena, 1898-México DF, 1966) ha sido hasta hace pocos años otro gran desconocido del periodismo andaluz de la primera mitad del siglo XX. Con un cuidado lenguaje periodístico, se convirtió pronto en uno de los más reconocidos columnistas del periodismo cordobés de los años veinte, siendo habitual su colaboración en distintos medios de comunicación de ámbito nacional durante la Segunda República y asumiendo destacadas responsabilidades cuando Juan Negrín fue nombrado ministro y después presidente del Gobierno de la República, momento en el que sería designado portavoz del consejo de ministros. Vázquez Ocaña fue también uno de los grandes defensores de la profesión periodística en Córdoba, reivindicando en los años veinte la mejora de las condiciones laborales de los trabajadores de los periódicos (5). Sus inicios se produjeron en el Diario Liberal, donde escribió durante más de una década (1920-1930), compaginando sus trabajos con la publicación de textos en otros diarios o semanarios como Diario de Córdoba, Andalucía llustrada o Revista Popular. Después llegaría la asunción de responsabilidades en periódicos cordobeses como Política (fue director en el semanario de este nombre y redactor jefe cuando se convirtió en diario) o El Sur, que fundó y dirigió. Ese protagonismo en la prensa cordobesa, tras ser elegido diputado por el Partido Socialista en 1933, se extendería al ámbito nacional al marchar a Madrid. Fue nombrado redactor jefe de El Socialista, que estaba bajo la dirección Julián Zugazagoitia, y, tras el levantamiento militar, ocuparía la dirección de La Vanguardia al trasladarse el Gobierno de Negrín a Barcelona, además de controlar otros diarios que se convirtieron en portavoces del Gobierno republicano. Sin embargo, con la dictadura franquista el periodista baenense fue olvidado por el franquismo y por el Partido Socialista al enemistarse con Indalecio Prieto y alinearse con las corrientes negrinistas (Expósito, 2015).

La defensa del periodista, pero también su integridad y compromiso con la Segunda República y con la figura de Juan Negrín en España y en el exilio serán constantes en Vázquez Ocaña. A través de algunos de sus artículos en el exilio (abandonó España en 1939 para ir a París y después, en 1940, se trasladó a México), se constata su reivindicación de la Segunda República y la democracia, convirtiéndose en un firme defensor de las libertades, aunque también cuestionó la paralización de las reformas durante el Gobierno de la derecha. En este contexto hay que destacar su libro Pasión y muerte de la Segunda República española (París, 1940), reeditado en 2007 por la Fundación Pablo Iglesias, que es un interesante análisis sobre la Segunda República, abordando los problemas que condujeron a la guerra civil española.

Vázquez Ocaña, tras la experiencia en España, continuó su vinculación con la prensa. Así, en México registró El Socialista, que dirigió desde 1942, además de impulsar y dirigir otros como República Española o la revista Higiene y Seguridad.

No obstante, cuando llegó a México se encontró con innumerables problemas económicos, ya que no pudo acceder, como sucedió con centenares de españoles, a profesiones en las que se demandaba una capacitación universitaria que no tenía. Por eso tuvo que recurrir a su capacidad como escritor para mantener a su familia (tenía ocho hijos), colaborando y promoviendo distintos medios, pero también escribiendo en editoriales como Grijalbo.

Su trayectoria se ve engrandecida, además, porque fue uno de los primeros grandes biógrafos de Federico García Lorca al publicar el libro García Lorca. Vida, cántico y muerte (dos ediciones), lo que sería destacado por lan Gibson:

Vale la pena indicar que Adolfo Salazar no aludió en su reseña-como tampoco Mora Guarnido en la suya- a la angustia erótica que trasmina casi cada composición de Libro de poemas y que era difícil no reconocer. ¿Tal omisión correspondía más a razones de prudencia que a las de una momentánea ceguera crítica? Cabe pensarlo. Pero fuera así o no, pasarían más de cuarenta años antes de que un crítico empezara a sospechar lo que pudiera haber en este libro, o algo de ello. Se trata de F. Vázquez Ocaña (Gibson, 2008: 170).

La biografía escrita por Fernando Vázquez Ocaña se convirtió en 1957 en una de las primeras grandes publicaciones editadas sobre el escritor andaluz en el exilio (en 1962 tendría una segunda edición). Vázquez Ocaña elabora una cuidada publicación en la que contextualiza la vida del poeta granadino con su obra, 
además de aportar algunas anécdotas personales de los encuentros que mantuvo con García Lorca, que no se conocerían de no haber sido por el periodista baenense. El periodista estuvo en varias ocasiones con el escritor, acompañándolo en una de sus últimas visitas a Córdoba en 1935.

Su vinculación con Andalucía no la olvidó nunca. Fue responsable de Cultura del Centro Andaluz en México y en 1943 pronunció una conferencia en la capital mexicana sobre la evolución e importancia de Andalucía en la cultura. Con el título de "Elogio de Andalucía", resaltará el carácter de esta tierra:

El andaluz se puede decir que representa un punto de equilibrio en la civilización, como lo representó el griego de la época platónica y el francés del siglo XVII. Su característica es saber rodearse de valores llenos de gracia y mirar las cosas por el lado del señorío (...) (Vázquez Ocaña, 2015).

En sus primeras palabras trata de sentar las bases sobre los retos del Centro Andaluz en México para evitar las diferencias políticas:

Hemos de hacer también una afirmación previa: la de que el espíritu que preside esta tribuna no se verá empañado por resabios políticos ni, muchos menos, manifestará tendencias diferencialistas o instintos centrífugos respecto a la unidad española (Vázquez Ocaña, 2015).

El recuerdo de España estuvo siempre presente, pese a la lejanía, pese a los muertos de las cunetas y los amigos que se quedaron allí. También su deseo de regresar, aunque fue imposible. Fernando Vázquez Ocaña soñará muchos días con la patria común, alejada de los nacionalismos, como gran defensor que era de la unidad de España y de la mezcla de culturas y poblaciones para crecer y sugería la idea del federalismo como la mejor relación posible. En la conferencia sobre Andalucía, el periodista baenense reiterará su postura en unos años de cisma entre los exiliados españoles:

Aprovechamos, por lo tanto, esta oportunidad para lamentar el énfasis agresivo que los gonfalonieros de otras regiones españolas prestan a sus ideales de autonomía, comprometiendo no solo los requisitos de la reconstrucción de la gran patria común, sino hasta la misma legitimidad de sus concepciones políticas, al elevarlas de rango sin el menor respeto al interés general de España". Ante numerosos andaluces y españoles exiliados en México, finalizaba su Elogio de Andalucía con las siguientes palabras: "Nuestras viñas siguen dando zumo. Hoy el montón de cenizas se ha henchido con las de muchos oscuros mártires. Quizás la risa haya muerto y la soledad se ha hecho más profunda. Pero allí está la tierra con sus olivos y sus viñedos. Los rostros de las vírgenes de las iglesias se habrán vuelto más humanos. ¿Qué nos reclaman las voces lejanas? Seguir fieles a nuestro gracioso espíritu. Que de lo hondo de nuestro ser surja, mandato de vivos y muertos, este laude: ANDALUCÍA NUESTRA, QUE ESTÁS EN LA TIERRA... (Vázquez Ocaña, 2015).

\subsection{Manuel Piedrahita Ruiz}

Manuel Piedrahita Ruiz (Málaga, 1907-Baena, 1936) impulsó la prensa local tras comenzar sus colaboraciones en Regeneración o Diario Liberal. En Madrid estudió en la escuela de periodismo de El Debate, fundó en 1930 en Baena La Defensa y dirigió periódicos en Zamora y Jaén. En 1934 promovió y dirigió el periódico local Nuevas, uno de los tres grandes periódicos baenenses de los años treinta junto a La Defensa y Todos. De familia de labradores, Manuel Piedrahita Ruiz nació de manera "circunstancial" en Málaga, como ocurría en aquella época cuando las familias bien situadas decidían trasladarse a una clínica para recibir una atención adecuada al ser limitado el servicio que se prestaba en Baena. El joven Manuel ingresó en la Academia Militar de Toledo cuando tenía 15 años, aunque esta vocación pronto la abandonó. De vuelta a Baena, Manuel Piedrahita defendió su interés por la escritura frente a la gestión de las tierras familiares. Así inició sus colaboraciones, con 19 años, en el periódico Regeneración. En 1927 marchó a Madrid para estudiar periodismo en la escuela del periódico El Debate, aunque seguía colaborando con Regeneración y Diario Liberal. El 24 de abril de 1930 apareció el primer número del periódico 'La Defensa. Semanario Popular', que fue fundado por Manuel Piedrahita, figurando como redactor jefe. Mantuvo esta responsabilidad en siete números. Fue director de El Correo de Zamora, perteneciente a la misma empresa que El Debate. El 1 de abril de 1932 apareció el periódico jiennense La Mañana, que tendría como director a Manuel Piedrahita. Dimitió a finales de septiembre. Entonces fundó en Jaén el periódico Nuevas, precedente del que después impulsaría en 1934 en Baena. Antonio Checa Godoy, en su libro Historia de la prensa jiennense (1808-1983), definió a Piedrahita como un 
"hombre conservador pero independiente" (Checa, 1986: 186), destacando la independencia de la edición de Nuevas en Jaén:

Nuevas publicaría solo 99 números, como indicábamos. Cesaba el 23 de septiembre del mismo 1933, a pocas semanas curiosamente de las elecciones generales de noviembre de ese año. Mostró siempre una orientación moderada; periódico independiente, esencialmente informativo y poco político, obtendría por ello algún piropo de su colega socialista Democracia (probablemente asombrado de ver una derecha civilizada, como hoy calificaríamos el intento de Piedrahita) (Checa, 1986: 186).

El periodista regresaría a Baena y puso en marcha una nueva edición de Nuevas, que desapareció por problemas económicos en el número 70, de diciembre de 1935. "Él no quiso marcharse al ayuntamiento como le requirió el teniente de la guardia Civil, Pascual Sánchez Ramírez. "Yo siempre he defendido a los obreros del campo», decía. Vivía en la calle Mesones, justamente hasta donde llegaron los campesinos amotinados que lo llevaron a San Francisco", nos aseguraría su hijo, el también periodista Manuel Piedrahita Toro.

\subsection{Antonio de los Ríos Urbano}

Nacido en 1899, fue el primero y el último alcalde de la Segunda República en Baena. Propietario y director del semanario socialista La Defensa, después impulsó Lex. La declaración de principios de La Defensa dejaba clara la modernidad de la publicación, que trataba de superar mentalidades rancias y propugnaba el desarrollo social y económico del municipio en cordobés:

Baena clama ya por una hoja periódica titulada a la masa popular, a la industria, al comercio, al trabajo; Baena detenta concepciones oligarcas; Baena se conduele aún de rancios procedimientos de gobierno, de vicios pasados, y suspira por una nueva era... (La Defensa, 24-4-1930)

Su primer mandato como alcalde transcurrió entre junio de 1931 y junio de 1933. De nuevo ocuparía la Alcaldía en el gobierno municipal que se aprobó el 20 de mayo de 1936, manteniéndose, a pesar de dimitir en el cargo y reiterar su renuncia, hasta el 17 de julio. Sin embargo, este periodo estuvo ya marcado por la difícil situación social y de auténtica preguerra que dominaba el país. Antonio de los Ríos, en un escrito leído en el Pleno municipal del 3 de julio de 1936, en el que presentaba su dimisión, ya aventuraba lo que podría suceder después:

Patentizaba el malestar latente en el orden social agudizado últimamente que hace vislumbrar horizontes sombríos, no sólo para la tranquilidad pública y los intereses generales de la población, sino que el estado de violencia que se avecina ha de responder el poder público con la misma medida y siendo opuesto a que los problemas sociales se resuelvan en forma que escapa a los límites de ponderación y sensatez que es obligada por todo lo que formula la renuncia de la Presidencia.

Su hermano, el general Adolfo de los Ríos, se alió desde el primer momento con el bando nacional que se levantó contra la Segunda República. Su posición como militante del Partido Socialista y con grandes responsabilidades en la política local no debió ser fácil cuando, cerca ya el levantamiento franquista, presentó su dimisión y se marchó de la localidad. Antonio de los Ríos desaparecía de la vida pública. Poco se supo de él después, sólo que tuvo tres hijos y que falleció en Cabra en 1947. Por el contrario, su hermano Adolfo recibió los más grandes reconocimientos de Baena al ser distinguido con la medalla de plata de la ciudad y rotularse una calle con su nombre, que ya le fue retirada.

\subsection{Ramón de Prado Santaella}

La figura de Ramón de Prado Santaella ha permanecido olvidada, pese a que fue uno de los grandes impulsores de la cultura en el sur de Córdoba durante la Segunda República. Licenciado en Filosofía y Letras, promovió el periódico Hoy (1931) y después Lema (1936) y colaboró el periódico cordobés Diario Liberal. Además, fue promotor de la Asociación Artística Talía, que tuvo una gran actividad por los pueblos cordobeses en 1935 y 1936.

El primer número del periódico Hoy. Semanario baenense se publicó el 12 de agosto de 1931. La redacción y la 
administración se encuentra en la Plaza de Pablo Iglesias, 2. En el número 4, publicado el 1 de septiembre de 1931, Ramón de Prado reniega de los sanchezguerristas y se declara republicano y afín con el socialismo:

Yo personalmente declaro que no pertenezco a ningún partido, que sólo soy ahora amante de la República y simpatizante con el socialismo. Mañana, cuando se haya estabilizado el actual régimen español y los partidos, en germen, tomen vida y cada partido dé a conocer su programa y sus hombres, entonces, no sé por cuál me decidiré, después de meditar bien sobre cada uno de ellos. Desde luego, sanchezguerrista me parece que no seré nunca, criterio que comparten conmigo mis dos compañeros de redacción con los que no ha surgido nunca, ni queremos que surja, ninguna discrepancia (Hoy, 1-9-1931).

Sin embargo, cuando se produjo el golpe de Estado, pesó más la intransigencia y que procedía de una familia acomodada de la localidad. Fue apresado y asesinado en el convento de San Francisco. Era el 28 de julio de 1936. Tenía 33 años.

\subsection{Daniel Aguilera Camacho}

Periodista conservador, director y propietario del periódico católico El Defensor de Córdoba, rápidamente se unió al golpe de Estado. Su periódico desapareció en 1938, aunque siguió escribiendo algún trabajo de investigación en el Boletín de la Academia de Córdoba, donde era académico. Daniel Aguilera Camacho, que fue el primer seglar que dirigió un periódico católico en la provincia, se marchó pronto de Baena. Pasó su infancia bajo el cuidado de su abuela tras fallecer su madre. Nacido en 1877, inició estudios eclesiásticos y en el seminario promovió un periódico. Sin embargo, en 1896 se alistó en el ejército, recalando en San Juan de Puerto Rico y Aibonito. Dos años después fue repatriado, reiniciando sus estudios eclesiásticos que, por la muerte de su padre, tuvo que abandonar para garantizar el sostenimiento de sus hermanos. Bajo seudónimo, comenzó a escribir en periódicos como El Español, Diario de Córdoba o El Defensor de Córdoba. En este periódico, que se creó en septiembre de 1899 en la capital cordobesa, comenzó a escribir a los once meses de su fundación. Su ascenso fue rápido, pues en abril de 1902 ya aparecía como director interino y poco después le fue transferida la propiedad. Junto a su catolicismo, Daniel Aguilera se caracterizó durante toda su trayectoria por la defensa de las viejas costumbres, además de combatir las injurias a la patria, al ejército, la religión o la monarquía.

Uno de los periódicos más críticos con la Segunda República fue, precisamente, El Defensor de Córdoba, que no aceptó el nuevo sistema de gobierno y los cambios que se estaban produciendo desde su ideología como periódico católico. El periódico se vio sometido a la censura durante el bienio progresista y hasta su director llegó a ser detenido (lo arrestaron el 19 de agosto de 1932 y lo liberaron al día siguiente), además de suspenderse el periódico durante 13 días. En 1931, recién proclamado el nuevo sistema de gobierno, publicó una columna editorial, titulada "Nosotros", en la que defendía su postura como periódico "católico, apostólico, romano" y su defensa de "Dios y la patria":

Nosotros somos lo que hemos sido siempre: católicos, apostólicos, romanos. Nuestra actuación seguirá siendo lo que ese nombre nos manda. Ante todo y sobre todo es para nosotros Dios, el amor a Dios y a su Santísima Madre y la defensa de la Religión Católica (El Defensor de Córdoba, 15-4-1931).

El posicionamiento favorable al golpe de estado de Franco se refleja al día siguiente del alzamiento nacional. En grandes tipografías titula: “¡Alea jacta est!”. El diario dirigido por Daniel Aguilera escribe en sumarios:

El ejército se alza contra el gobierno del frente popular. Declara que su programa es salvar a España de la anarquía. Los vibrantes vivas a España se repiten en todas las emisiones. El general Franco jefe militar del movimiento. Hay dos crisis en pocas horas: gabinete de M. Barrios y Giral. Los gobiernos de Casares, Martínez Barrio y Giral piden apoyo a los marxistas (El Defensor de Córdoba, 19-4-1936).

Un año después del golpe de Estado, el periódico defendía el alzamiento militar y exigía que no vacilara el Estado ante lo que consideraba que era "el amanecer de mañana". El diario aseguraba entonces que había sido el único periódico antirrepublicano de Córdoba:

Vivíamos una semana de inquietudes. El infame asesinato de Calvo Sotelo sobrecargó la atmósfera. Nosotros 
publicamos el periódico bajo una censura implacable. La historia del Defensor, único periódico antirrepublicano de la provincia, hacía que nuestros escritos fuesen más remirados porque en todo se sospechaba algo contra la república, esa república que tenemos a honor no haber formado nunca en sus filas, sino haber dado uno y otro día pruebas patentes de que nada queríamos con ese odiado régimen (El Defensor de Córdoba, 18-4-1937).

El 30 de septiembre de 1938 se publicaba el último número del periódico al no poder hacer frente al decreto sobre plantillas y sueldo de los periódicos. En ese último número reitera su posición antirrepublicana:

Los que seguían caminos paralelos al nuestro, muchos que hablaban de ideales análogos, nos abandonaron cuando la república se apoderó como un ladrón del poder, entrando por la ventana de unas elecciones municipales el 1931. Si no hubiéramos pensado en el deber que es sacrificio, pero es también satisfacción al alma, ante el déficit de varios miles de pesetas que trajo a nuestro presupuesto la república, hubiéramos enmudecido (El Defensor de Córdoba, 30-9-1938).

En su portada termina reconociendo su ideal católico y su exaltación de Franco, al que llama "salvador de nuestra España". Daniel Aguilera Camacho falleció en Córdoba el 19 de abril de 1955, a los 79 años de edad.

\section{EL NOTARIO NICOLÁS ALCALÁ ESPINOSA}

Nicolás Alcalá Espinosa, que nació en Baena el 15 de enero de 1885, era notario de profesión. Colaboró en la prensa de Madrid de las primeras décadas del siglo XX y se convirtió en uno de los grandes conocedores del aceite de oliva, llegando a presidir la Asociación Nacional de Olivareros de España. Alcalá Espinosa reflejó su visión de Andalucía a través de la reseña publicada en el periódico El Sol del libro Historia de las Agitaciones campesinas andaluzas, escrito por Díaz del Moral:

Muchos extraños y aun los propios piensan que Andalucía es casi España-desde luego, la más destacada y pintoresca de sus regiones- $y$ no hay que agregar que sobre ella se han volcado los más elegantes y los más torpes desatinos, hasta tal extremo, que han llegado a deformar la visión de los indígenas mismos.

Es frecuente encontrar andaluces que no saben de su andalucismo otra cosa que la leyenda de la alegría, los toros, la manzanilla, los ojos negros relampagueantes de las mujeres, y al fondo, hambre, miseria, inicua explotación del campesino..., cárceles, saetas, cante jondo en suma.

José Ortega y Gasset es el único que nos ha dicho verdades, sutilmente envueltas en la belleza incomparable de su estilo.

Libros como el del Sr. Díaz del Moral servirán para evitar la perduración de la pandereta literaria. La Andalucía estudiada, vista en su libro, es la Andalucía verdadera, la auténtica, con sus calidades y sus defectos, sus explosiones súbitas y sus letargos seculares (El Sol, 24-3-1929).

El notario cordobés defenderá en una conferencia pronunciada en Jaén una gestión adecuada de la Segunda República:

Se ocupó también del advenimiento de la República, diciendo que ésta vino como satisfacción nacional, y no traída por un partido. Por eso, al haber colaborado la mayoría de los españoles al advenimiento de ella, tenemos derecho ahora a administrarla y controlarla (ABC, 19-2-1932).

Fue elegido diputado en 1933 por la circunscripción de Jaén por el Partido Radical (obtuvo 142.407 votos). Su baja como diputado se produjo el 7 de enero de 1936.

Alcalá Espinosa se convirtió en un destacado especialista del sector del aceite de oliva en esos años, analizará los problemas que afectaban al sector, advertirá de las dificultades de competir con Italia, país al que cuestionaba que hiciera mezclas con los aceites y los refinara para responder a sus mercados, etiquetándolo ya entonces como propio. Asimismo, defiende la creación de una Federación Internacional del Aceite de Oliva. En una conferencia pronunciada en la Sociedad de Amigos del País, de Madrid, el 3 de abril de 1934, abordará la 
situación de los mercados y las debilidades de España:

Italia, que es el país más fuerte, no produce todo el aceite que consume. Para ello tiene que acudir a la mezcla y a comprar el producto en bruto para refinarlo y colocarlo con sus marcas. La lucha contra el aceite de procedencia italiana es casi imposible, porque este país ejerce de hecho un dumping, por medio de corporaciones, para envilecer los precios en el exterior y mejorar los del interior. Si España no hace el dumping, no podrá concurrir al mercado extranjero (...) Nuestro Gobierno tiene que adoptar una resolución y hacer que la sigan todos los olivareros. El comercio libre no se puede mantener en la actualidad. Deben ir de común acuerdo los productores y los comerciantes en gran escala -que no son más de cincuenta personas- (...) O España organiza su producción y comercio del aceite en inteligencia con los países mediterráneos o nuestra riqueza olivarera perece (El Sol, 4-4-1934).

Precisamente, en una entrevista publicada en El Sol dos meses antes, Alcalá Espinosa demandará una mayor organización del sector del aceite y más presencia internacional:

El problema del aceite es uno de los problemas de la economía española, y no es de hoy ni de ayer: es de siempre. Es, como todo el problema del agro español, problema de organización. Así lo entendieron los Gobiernos de la República cuando legislaron sobre los casos concretos del vino y del arroz, que por su volumen, por su influencia en la balanza comercial de nuestro país, debian haber sido atendidos hace tiempo (El Sol, 6-2-1934).

Fue asesinado en Madrid el 19 de octubre de 1936.

\section{LA ÚLTIMA PÁGINA}

Mientras se sucedían los homenajes franquistas, los republicanos que sobrevivieron, en el exilio interior o en otros países, siguieron añorando sus años en España, lamentando la imposibilidad de regresar a la ciudad donde nacieron porque eran considerados enemigos. Se abrieron heridas que una verdadera memoria histórica debería curar, sin parcialidades. Quizás un día regrese Fernando Vázquez Ocaña a España. Hoy, sus restos acompañan a los de otros muchos exiliados republicanos en el Panteón Español de México DF, donde yacen muchas ilusiones frustradas por el golpe militar, donde se encontrará siempre el espíritu de libertad de quienes pudieron huir del franquismo por soñar una España en democracia y no perecieron por la sinrazón del franquismo. En ese cementerio, en la populosa capital de acogida republicana hay muchos españoles olvidados por el paso del tiempo, entre ruinas de tumbas, convertidos en un número de registro almacenado en un archivo.

Los libros de texto y la historia han comenzado a recordar a los que quedaron abajo, como diría Fernando Vázquez Ocaña, y rememoran que hubo un tiempo no muy lejano en el que una gran parte de España luchó contra el totalitarismo franquista, pero también contra el nazismo y el fascismo. Será, nada más y nada menos, la gratitud de todos por soñar y tratar de no permitir lo que hace no muchas décadas llevó a España al holocausto.

\section{REFERENCIAS BIBLIOGRÁFICAS}

BEDMAR, A. (2013). Baena, roja y negra. Guerra civil y represión (1396-1943). Lucena, Juan de Mairena, y de libros.

CHECA, A. (1986). Historia de la prensa jiennense (1808-1983). Jaén, Diputación Provincial de Jaén, p. 186.

EXPÓSITO, F. (2015). El artículo político en Fernando Vázquez Ocaña durante su etapa en Córdoba (19301934). Tesis doctoral inédita, defendida el 9 de junio de 2015 en la Facultad de Comunicación de la Universidad de Sevilla, bajo la codirección de Antonio Ramos Espejo y María José Ruiz Acosta.

EXPÓSITO, F. (2016). "Manchas de sangre en papel de periódico. 1936: el año que se enterró la libertad de 
expresión en Baena" conferencia dictada durante el ciclo VI Jornadas de Historia de Baena y su entorno. La divulgación del pasado desde la escuela. IES Luis Carrillo de Sotomayor, 18 de febrero de 2016.

GIBSON, I. (2008). Vida, pasión y muerte de Federico García Lorca, 1898-1936. Barcelona, Debolsillo, p. 170.

SALA ROSE, R. y GARCÍA-PLANAS, P (2014). El marqués y la esvástica. Cesar González-Ruano y los judíos en el París ocupado. Barcelona, Anagrama, pp, 129-130.

SÁNCHEZ LISSEN, R. (coord.). Economía y economistas andaluces. Siglo XVI al XX (2013). Madrid, Ecobook., pp. 573-585.

SINOVA, J. (2006). La prensa en la Segunda República española. Historia de una libertad frustrada. Madrid, Debate, p.417.

TORRICO LOMEÑA, A. (2011). Baena durante la II República. Sus Ayuntamientos. Baena, Grupo Cultural Amador de los Ríos.

VÁZQUEZ OCAÑA, F. (2015). Elogio de Andalucía. Conferencia impartida el 6 de mayo de 1943 en el Centro Andaluz de Méjico. Prólogo y semblanza de Francisco Expósito. Baena, Grupo Cultural Amador de los Ríos.

VÁZQUEZ OCAÑA, F. (1957). García Lorca. Vida, cántico y muerte. México DF, Biografías Gandesa.

VÁZQUEZ OCAÑA, F. (2007). Pasión y muerte de la Segunda República española. Madrid, Biblioteca de la Cátedra del Exilio.

VELARDE, J.; DE DIEGO, E.; SÁNCHEZ LISSEN, R. y CANSINO, J.M. (2008). Antonio Bermúdez Cañete. Periodista, Economista y Político. Madrid, Actas.

\section{FUENTES HEMEROGRÁFICAS}

a) Periódicos locales

-Trabajo

-Regeneración
-La Defensa
-Todos
-Hoy
-Nuevas
-Lema
-Tambor
-Cancionero

b) Periódicos provinciales

-Diario Liberal

-Diario de Córdoba 


\section{-El Defensor de Córdoba}

-Política

-La Voz

-El Sur

-Guión

-Córdoba

-Sol de Andalucía

c) Periódicos nacionales

-El Debate

-El Socialista

$-A b c$

-La Vanguardia

$-E l$ Sol

(1) En un texto sin editar de Manuel Cubillo Jiménez escribía en 1956: “¿Y mi mujer y mis hijos?”. La respuesta fue rotunda. Los habían matado a todos (...). Luego lo supe todo. Los habían matado a golpes de hacha. Aquel de siete años, que siempre me recordaba al Ángel de la Oración de Murcia, a mi niña con cinco, y al otro con tres. A éste lo asesinaron en la falda de su madre, que moderna Virgen de las Angustias, lo vio morir en sus brazos, expirando juntos".

(2) Bedmar, A (2013). Baena, roja y negra. Guerra civil y represión (1936-1943). Lucena, Juan de Mairena, y de libros.

(3) Las medallas de la ciudad le fueron retiradas a Francisco Franco, Eduardo Sáenz de Buruaga y Pascual Sánchez tras aprobación del Pleno municipal del Ayuntamiento de Baena el 26 de noviembre de 2015.

(4) Expósito, F. “Un siglo de periódicos en Baena” en el Cancionero, enero, febrero, marzo y abril de 2006.

(5) Expósito, F. “Vázquez Ocaña, el defensor de la profesión periodística” en el diario Córdoba, 7 de julio de 2013.

\section{BREVE SEMBLANZA DEL AUTOR}

Francisco Expósito Extremera es Doctor en Periodismo por la Universidad de Sevilla, Redactor de Diario Córdoba.

Ámbitos. Revista Internacional de Comunicación, n.31, edición de invierno, 2016.

Recibido: 26/03/2015

Aprobado: 25/04/2015 